\title{
Analysis of Economic Efficiency and Farm Size: A Case Study of Wheat Farmers in Nakuru District, Kenya
}

\author{
Samuel Mburu, ${ }^{1}$ Chris Ackello-Ogutu, ${ }^{2}$ and Richard Mulwa ${ }^{2}$ \\ ${ }^{1}$ Department of Household and Consumer Economics, Universität Hohenheim, Fruwirthstraße 48, 70599 Stuttgart, Germany \\ ${ }^{2}$ Department of Agricultural Economics, University of Nairobi, P.O. Box 30197, Nairobi 00100, Kenya \\ Correspondence should be addressed to Samuel Mburu; mburusam@yahoo.com
}

Received 21 April 2014; Revised 17 August 2014; Accepted 20 September 2014; Published 16 October 2014

Academic Editor: Jean Paul Chavas

Copyright (c) 2014 Samuel Mburu et al. This is an open access article distributed under the Creative Commons Attribution License, which permits unrestricted use, distribution, and reproduction in any medium, provided the original work is properly cited.

\begin{abstract}
The primary objective of this study is to examine the effect of farm size on economic efficiency among wheat producers and to suggest ways to improve wheat production in the country. Specifically, the study attempts to estimate the levels of technical, allocative, and economic efficiencies among the sampled 130 large and small scale wheat producers in Nakuru District. The socialeconomic factors that influence economic efficiency in wheat production have also been determined. Results indicate that the mean technical, allocative, and economic efficiency indices of small scale wheat farmers are $85 \%, 96 \%$, and $84 \%$, respectively. The corresponding figures for the large scale farmers are $91 \%, 94 \%$, and $88 \%$, respectively. The number of years of school a farmer has had in formal education, distance to extension advice, and the size of the farm have strong influence on the efficiency levels. The relatively high levels of technical efficiency among the small scale farmers defy the notion that wheat can only be efficiently produced by the large scale farmers.
\end{abstract}

\section{Introduction}

The relationship between farm size and land productivity has been widely debated in literature for decades and several reasons and explanations for the inverse relationship between farm size and land productivity have been put forward and tested.

The first reason is imperfect factor markets including failures in the land market, credit market [1], insurance market [2], and labour market $[3,4]$. Malfunctioning or absence of these markets will lead to suboptimal resource allocation at the farm level implying inefficiencies. An important cause of labour market imperfections in developing countries is labour supervision cost; as hired labour is assumed to be less motivated and effective, it takes more productive family labour to supervise hired labour which decreases overall labour productivity at farm level [5]. This would explain why labour and farm productivity are lower on large farms, which require more hired labour. Studies by Assunção and Braido [4] and Barrett et al. [6] argue that the imperfect market hypotheses imply the presence of unobservable variation between households that leads to differences in the input intensity levels which are correlated with farm area. Therefore, they add a set of household-specific characteristics such as household size, dependency ratio, and gender of the household head in testing the inverse relation between farm size and productivity. However, no previous study has shown that household characteristics completely explain land productivity.

A second important explanation questions whether the land productivity between farm size and productivity emerges (or not) from omitted variables. Importantly, differences in soil quality lead to differences in soil productivity which clearly affect output with small farmers being more productive because of having plots of better quality. In addition, farming practices and production methods might vary according to farm size, leading to differences in yields and productivity $[4,7]$. All these studies show a decrease in the severity of land productivity when controlling for soil quality $[6,8]$, but none has found that the land productivity 
declines. Lipton [5] used differentiation in farm management skills as an explanatory variable of farm productivity using panel data which allows for household-specific fixed effects. However, the evidence does not suggest that managerial skills explain land productivity.

A third explanation of the land productivity is related to methodological issues. As one of the unsettled issues, Lipton [5] mentions that large farms cannot be considered linear replicas of small ones. Incentives to use inputs vary with production scale; that is, larger farms use different technologies than small farms. Most empirical studies on the land productivity are based on cross-sectional data and econometric models can fail to capture nonlinearities and often impose a common specification (parameters) for the whole sample. Moreover, the scale ranges that are allowed in the models may be too small to measure scale effects [9].

1.1. Background of the Study. Wheat is the second most important crop after maize in Kenya with regard to both production and consumption. Until the early 1970s Kenya was a net exporter of wheat but currently the country imports about $60 \%$ of the total domestic demand. Wheat is grown in the cooler and medium-rainfall regions covering the Nakuru, Uasin Gishu, Trans-Nzoia, and Narok districts and is mostly rain-fed. Production is carried out by small, medium, and large scale farmers numbering about 9000. The industry, supported by about 20 millers, contributes $1.4 \%$ and $30 \%$ to overall and cereal GDP, respectively. The small scale farmers are the majority of the producers but their production accounts for only one-quarter of the total wheat produced. The domestic demand for wheat is growing at the rate of $7 \%$ per year even though production is increasing marginally. Wheat and its by-products have gained importance in the households' consumption patterns in the last decade. In 2005 wheat and its by-products accounted for $44 \%$ of total expenditure of main staples in urban areas, up from 35\% in 1999 [10]. Kenya is a high cost wheat producer and, for this reason, the country requested the Common Market for Eastern and Southern Africa (COMESA) for safeguard measures to allow the country to address weaknesses in competitiveness of the subsector.

The increasing domestic demand for wheat is driven largely by the rapidly growing population, increased urbanization, rising incomes, and a change in food preferences from traditional cereals towards wheat and wheat products. Though the country has the potential of increasing the production of wheat, the sector is faced by several challenges, notably: expensive inputs (chemicals, seeds, and fertilizers); insufficient farm machineries; high fuel prices; unstable producer prices; and subdivision of large scale farms into smaller units. The small scale farmers are the majority of the producers but they differ significantly in the use of inputs, agronomic practices, and productivity from the large scale farmers [10]. The actual levels of efficiency and sources of inefficiencies among the different size categories are, however, unknown. Measuring economic efficiency in wheat production is important for a number of reasons: the significance of the subsector in terms of farm incomes to the rural economy; regional integration (more open borders, especially under COMESA and the East African Cooperation) is spawning higher levels of competition that require increased production and distribution efficiency; and the importance of the subsector to the country's strategies relating to achievement of broad food self-sufficiency, rural employment creation, and poverty reduction.

Following the experiences of the 2007/08 global food crisis when many food net-importing countries, especially those in sub-Saharan Africa, were unable to secure supplies from the international market, the country has embarked on an aggressive plan to boost its domestic food production under the auspices of the Agriculture Sector Development Strategy (ASDS). This is essentially an import substitution strategy that requires increased investments to the agriculture sector, reformation of the agricultural research and information dissemination systems, and improving access to credit in order to increase technological innovation particularly among the growers of the major cereal grains (maize, wheat, and rice).

1.2. Objectives of the Study. The analysis of the link between economic efficiency and farm size in Kenya is partly motivated by the increasing pressure on agricultural land that arises from increasing population and the persistence of high rural populations despite increasing urbanization. Agricultural land is also under pressure from other sources: climate change that aggravates the already diminished fallow periods due to fragmentation in the more populous and high rainfall potential regions; declining soil fertility; and the need for equity in land ownership that brings the large wheat farms into high prominence. The study therefore addresses an important question of whether or not there are significant economic efficiency differences between large scale farms and smallholder units that are the most likely to predominate in the future as the different pressures mount on the land resource.

The general objective of this study is to examine the effect of farm size on economic efficiency among wheat producers in Nakuru District and to suggest ways to improve wheat production in the country. The specific objectives are to estimate the levels of technical, allocative, and economic efficiencies among the large and small scale wheat producers; to assess the effect of farm size on technical, allocative, and economic efficiency; and to determine socioeconomic factors influencing efficiency among small and large scale wheat producers. The following null hypotheses will be tested:

$$
\begin{aligned}
& \mathrm{H}_{0} \text { : farm size has no effect on economic efficiency; } \\
& \mathrm{H}_{0} \text { : none of the identified socioeconomic factors influ- } \\
& \text { ences efficiency. }
\end{aligned}
$$

\section{Farm Size and Efficiency}

Several studies have investigated the levels of technical and allocative efficiencies on various farm enterprises with different findings. Obare et al. [11] applied a dual stochastic efficiency technique and a two-limit Tobit model to analyze resource allocative efficiency in Irish potato production in 
Kenya. The authors established that Irish potato production in Nyandarua North District is characterized by decreasing returns to scale with a mean allocative efficiency of 0.57 . The paper further established that farming experience, access to extension and credit, and membership in a farmers' association positively and significantly influenced allocative efficiency.

Mulwa et al. [12] used a two-step estimation technique (DEA metafrontier and Tobit Regression) to highlight the inefficiencies in maize cultivation and their causes in Western Kenya. The study found that farmers could reduce their input use by about $20-30 \%$ and still achieve their current production level. The costs could be reduced by over $50 \%$ without affecting production thereby indirectly increasing the farmers' incomes. A study by Abate et al. [13] applying a stochastic frontier model in Ethiopia found that tenure status significantly influences technical efficiency. The authors report that more than half of the farmers cultivating wheat on their own plots operated above the average efficiency level compared to less than one-quarter for those cultivating on borrowed plots. Beside land tenure systems, several other social economic and resource factors were identified to have an influence on technical efficiency. Technical efficiency was higher for older farmers due to experience gained over time. Male headed households were found to be more efficient than female headed households and households with more educated heads were found to be more efficient. This study however had its emphasis on wheat production and the results would not be generalized to other enterprises.

Ogundari and Ojo [14] estimated technical and allocative efficiency of smallholder crop farmers in Nigeria using Cobb Douglas production and cost functions. The finding of the study was that farmers operated under increasing returns to scale and therefore had the potential of improving their efficiency. The educational level of the head of farmer (schooling years), farm size, quantity of fertilizer, age of farmer, credit availability, and farming experience of the farmer were found to influence technical efficiency significantly.

The evidence on the farm-size efficiency relationship is mixed. It is important to clearly define the terms and methodologies adopted in investigating the relationship between farm size and the efficiency of farms based on the particular region. Most frontier studies have focused only on technical efficiency even though it is by improving overall economic efficiency that major gains in output could be achieved. The few studies reviewed above suggest there is still a gap in our understanding of the relationship between farm size and economic efficiency. This paper attempts to fill the gap by examining overall efficiency on wheat production.

2.1. Theoretical Framework. This study uses the parametric stochastic efficiency technique that follows the Kopp and Diewert [15] cost decomposition procedure to estimate technical, allocative, and economic efficiencies. Its advantage lies in the application of a stochastic frontier model with a disturbance term specification that captures noise, measurement error, and exogenous shocks beyond the farm. The two-step regression model has been used to analyze the effects of the social-economic factors on economic efficiency using a censored Tobit model.

Over fifty years ago, Farrell [15] introduced a methodology to measure economic efficiency (EE), technical efficiency (TE), and allocative efficiency (AE; by definition, EE is equal to the product of TE and AE). According to Farrell, TE is associated with the ability to produce on the frontier isoquant, while $\mathrm{AE}$ refers to the ability to produce at a given level of output using the cost-minimizing input ratios (Figure 1). Alternatively, technical inefficiency is related to deviations from the frontier isoquant, and allocative inefficiency reflects deviations from the minimum cost input ratios. Thus, EE is defined as the capacity of a firm to produce a predetermined quantity of output at minimum cost for a given level of technology $[15,16]$. Productive units can be inefficient either by obtaining less than the maximum output available from a determined set of inputs (technical inefficiency) or by not purchasing the lowest priced package of inputs given their respective prices and marginal productivities (allocative efficiency). Efficiency measurement can be categorized as either input or output oriented: input-oriented technical efficiency evaluates how much input quantities can be reduced without changing the quantities produced while output-oriented measures of efficiency estimate the extent to which output quantities can be expanded without altering the input quantities used [17]. Efficiency estimation can best be demonstrated by relating both allocative and technical efficiency, Farrell's methodology has been applied widely while undergoing many refinements.

\section{Empirical Framework: Stochastic Frontier Production and Cost Functions}

As in Bravo-Ureta and Evenson [18] and Bravo-Ureta and Rieger [19], the parametric technique used in this study follows the Kopp and Diewert [15] cost decomposition procedure to estimate technical, allocative, and economic efficiencies. The firm's technology is represented by the stochastic frontier production function as follows:

$$
Y_{i}=f\left(X_{i} ; \beta\right)+e_{i}
$$

where $Y_{i}=$ the output of the $i$ th farmer, $X_{i}=$ a vector of input quantities of the $i$ th farmer, and $\beta=$ a vector of unknown parameters to be estimated. Consider the following:

$$
e_{i}=\left(V_{i}-U_{i}\right)
$$

The $V_{i}$ are assumed to be independent and identically distributed $N\left(0, \sigma_{v}^{2}\right)$ random errors independent of the $U_{i}$. The $U_{i}$ are nonnegative technical inefficiency effects representing management factors and are assumed to be independently distributed with mean $u_{i}$ and variance $\sigma_{2}$. The $i$ th farm exploits the full technological production potential when the value of $U_{i}$ comes out to be equal to zero, and the farmer is then producing at the production frontier beyond which he cannot produce. The greater the magnitude of $U_{i}$ from the production frontier, the higher the level of inefficiency of 


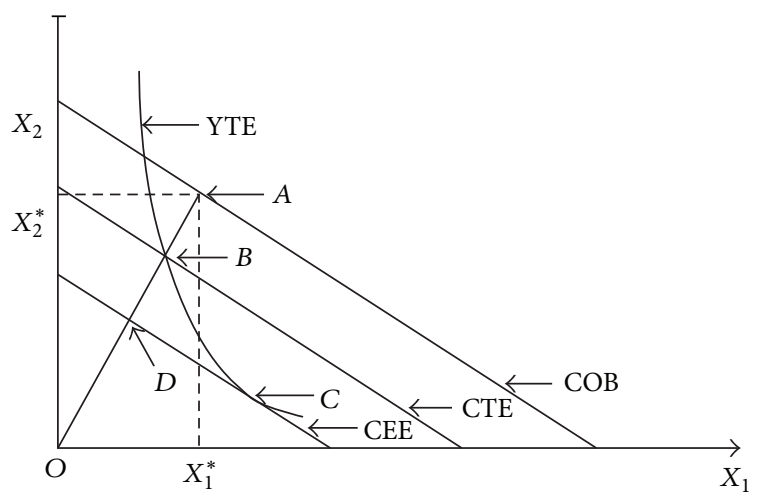

YTE: technically efficient isoquant

CTE: technically efficient cost

CEE: economically efficient cost

COB: observed cost

FIgURE 1: Graphical Representation of observed and technically and economically efficient cost Measures. Technical efficiency (TE), allocative efficiency (AE), and economic efficiency (EE) are equal to the following: $\mathrm{TE}=\mathrm{OB} / \mathrm{OA}=\mathrm{CTE} / \mathrm{COB}, \mathrm{AE}=\mathrm{OD} / \mathrm{OB}=$ $\mathrm{CEE} / \mathrm{CTE}$, and $\mathrm{EE}=\mathrm{TE} * \mathrm{AE}=\mathrm{OD} / \mathrm{OA}=\mathrm{CEE} / \mathrm{COB}$.

the farmer [20]. The maximum likelihood estimation of (1) provides estimators for the beta coefficients. The variances of the random errors $\sigma_{v}^{2}$ and those of the technical and allocative inefficiency effects $\sigma_{u}^{2}$ and overall variance of the model $\sigma^{2}$ are related; thus,

$$
\sigma^{2}=\sigma_{v}^{2}+\sigma_{u}^{2}
$$

The ratio $\gamma=\sigma_{u}^{2} / \sigma^{2}$ measures the total variation of output from the frontier which can be attributed to technical or allocative inefficiency [21].

Subtracting $v_{i}$ from both sides of (1) yields

$$
Y_{i}^{*}=y_{i}-v_{i}=f\left(X_{i} ; \beta\right)-U_{i},
$$

where $Y_{i}^{*}$ is the observed output of the $i$ th firm, adjusted for the stochastic noise captured by $v_{i}$.

Equation (4) is the basis for deriving the technically efficient input vectors and for analytically deriving the dual cost frontier of the production function represented by (1). For a given level of output $Y_{i}^{*}$, the technically efficient input vector for the $i$ th firm, $X_{i}^{t}$, is derived by simultaneously solving (4) and the ratios $X_{1} / X_{i}=k_{i}(i>1)$ where $k_{i}$ is the ratio of observed inputs $X_{1}$ and $X_{i}$. Assuming that the production function in (1) is self-dual, the dual cost frontier can be derived algebraically and written in a general form as

$$
C_{i}=f\left(P_{i} ; \alpha, Y_{i}^{*} ; \alpha\right)
$$

where $C_{i}$ is the minimum cost of the $i$ th firm associated with output $Y_{i}^{*}, P_{i}$ is a vector of input prices for the $i$ th firm, and $\alpha$ is a vector of parameters.

The economically efficient input vector for the $i$ th firm, $X_{i}^{e}$, is derived by applying Shephard's Lemma and substituting the firm's input prices and output level into the resulting system of input demand equations:

$$
\frac{\partial C_{i}}{\partial P_{i}}=X_{i}^{e}\left(P_{i} Y_{i}^{*} ; \beta\right) \quad i=1,2, \ldots, m \text { inputs, }
$$

where $\beta$ is a vector of estimated parameters.

The observed, technically efficient, and economically efficient costs of production of the $i$ th firm are equal to $P_{i}^{\prime} X_{i}$, $P_{i}^{\prime} X_{i}^{t}$, and $P_{i}^{\prime} X_{i}^{e}$, respectively. These cost measures are used to compute technical efficiency (TE) and economic efficiency (EE) indices for the $i$ th firm as follows:

$$
\begin{aligned}
& \mathrm{TE}_{i}=\frac{P_{i}^{\prime} X_{i}^{t}}{P_{i}^{\prime} X_{i}} \\
& \mathrm{EE}_{i}=\frac{P_{i}^{\prime} X_{i}^{t}}{P_{i}^{\prime} X_{i}} .
\end{aligned}
$$

Following Farrell [16], the allocative efficiency (AE) index can be derived from (7a) and (7b) as follows:

$$
\mathrm{AE}_{i}=\frac{P_{i}^{\prime} X_{i}^{e}}{P_{i}^{\prime} X_{i}^{t}}
$$

Thus the total cost or economic efficiency of the $i$ th firm $\left(P_{i}^{\prime} X_{i}-P_{i}^{\prime} X_{i}^{e}\right)$ can be decomposed into its technical $\left(P_{i}^{\prime} X_{i}-\right.$ $\left.P_{i}^{\prime} X_{i}^{t}\right)$ and allocative $\left(P_{i}^{\prime} X_{i}^{t}-P_{i}^{\prime} X_{i}^{e}\right)$ components.

3.1. The Production Function. A production function can be expressed generally as $Y=f\left(X_{i}\right)$, where $Y$ is output level per unit of time and $X_{i}$ denote quantities of different inputs. Using only labor $(L)$ and capital $(K)$ and other factors of production held constant (in the short run), we have $Y=f(L, K)$. Generally, labor units can be changed at a short notice but it takes more time to install machinery or equipment represented here by $K$. Production functions can be expressed in different forms depending on the technological relationship between $Y$ and $X$; indeed, the functional relationship between output and inputs is referred to as the firm's technology. Due to duality, knowledge of a firm's technology automatically reveals a firm's cost function (the relationship between $Y$ and total cost of all inputs including fixed costs). One of the most commonly used production function specifications for agricultural production relationships is the Cobb-Douglas function generally expressed as follows in the case of two inputs:

$$
Y=(L, K)=A L^{a} K^{b}
$$

where $A$ is a scale parameter (constant) and $a$ and $b$ are elasticity of output response due to changes in $L$ and $K$, respectively; the coefficients $a$ and $b$ are generally restricted to ensure that the technology exhibits decreasing returns to scale, thus allowing for a profit maximum.

A variation of the Cobb-Douglas function applied in this study is the stochastic frontier model defined in (10). (The Cobb-Douglas production form is chosen because its practicality and ease in the interpretation of its estimated 
coefficients. Despite its limitations of constant elasticity of substitution, the Cobb-Douglas is found to be an adequate representation of our data.) It is simply a linearization of the above general form using logs:

$$
\begin{aligned}
\ln Y_{i}= & \beta_{0}+\beta_{1} \ln \text { fert }_{1}+\beta_{2} \ln \text { seed }_{2} \\
& +\beta_{3} \ln \text { chem }_{3}+\beta_{4} \ln \text { foliar }_{4}+\beta_{5} \operatorname{ln~hlab}_{5} \\
& +\beta_{6} \ln \text { flab }_{6}+V_{i}-U_{i},
\end{aligned}
$$

where $\ln =$ natural logarithm; $Y_{1}=$ wheat output (in $\mathrm{kg}$ ) of the $i$ th farmer per acre; fert ${ }_{2}=$ quantity of fertilizer used in $\mathrm{kg}$ per acre; seed $_{2}=$ quantity of seeds used in kg per acre; chem $_{3}$ $=$ quantity chemicals used in $\mathrm{kg}$ per acre; foliar $_{4}=$ quantity of foliar used in liters per acre; hlab $b_{5}=$ cost of hired labor per acre; $\mathrm{flab}_{6}=$ imputed cost of family labor per acre; $v_{i}=$ random error; $u_{i}=$ inefficiency measure; and $\beta_{i}=$ parameters to be estimated.

The $u_{i}$ is the nonnegative truncation (at zero) of the normal distribution with mean, $\mu_{i}$, and variance $\sigma^{2}$. The variables specified in the model were subjected to a correlation test that showed that all the variables were not highly correlated.

3.2. The Cost Function. The economic cost of an input is the minimum payment required to keep the input in its present employment. It is the payment the input would receive in its best alternative employment. The corresponding dual stochastic frontier cost function which is the basis of estimating the allocative efficiencies of the farmers is specified as follows:

$$
C_{i}=f\left(P_{i} ; \alpha, Y_{i}^{*}+U_{i}\right) \quad i=1,2,3, \ldots, N,
$$

where $C_{i}=$ minimum cost of the $i$ th firm associated with output, $Y_{i} ; f=$ Cobb-Douglas functional form; $P=$ input prices employed by $i$ th farm in wheat production; $\alpha=$ parameter to be estimated; $Y_{i}^{*}=$ the observed wheat output per acre of the $i$ th firm adjusted for the statistical noise captured by $V_{i}$; and $U_{i}$ provides information on the levels of allocative efficiency of the $i$ th farm.

The Cobb-Douglas cost frontier function for the wheat farmers is specified as follows:

$$
\begin{aligned}
\ln C_{i}= & \alpha_{0}+\alpha_{1} \ln Y_{1}^{*}+\alpha_{2} \ln \text { pfert }_{2} \\
& +\alpha_{3} \ln \text { pseed }_{3}+\alpha_{4} \ln \text { pchem }_{4}+\alpha_{5} \ln \text { pfoliar }_{5} \\
& +\alpha_{6} \ln \text { phlab }_{6}+\alpha_{7} \text { pflab }_{7}+U_{i}
\end{aligned}
$$

where $C_{i}=$ total cost of production of $i$ th farm per acre; $Y_{1}^{*}$ $=$ observed wheat output per acre adjusted for statistical noise; pfert $_{2}=$ price of fertilizer per kg; $\operatorname{pseed}_{3}=$ price of seeds per kg; pchem $_{4}=$ price per liter of chemical; pfoliar $_{5}=$ price per liter of chemical; phlab $_{6}=$ wage rate per day; and $_{\text {pflab }}=$ imputed family labor per day.

3.3. Determining Factors Influencing Efficiency. Several authors have investigated the relationship between efficiency and various socioeconomic variables using two alternative approaches (for a review of several of these papers, see Bravo-Ureta and Rieger [19]). One approach is to compute correlation coefficients to conduct other simple nonparametric analyses. The second way, usually referred to as a two-step procedure, is to first measure farm level efficiency and then to estimate a regression model where efficiency is expressed as a function of socioeconomic attributes. Kalirajan [22] observed that socioeconomic attributes have roundabout effects on production and hence should be incorporated into the analysis directly while Ray [23] argued that the two-step procedure is justifiable if one assumes that production function is multiplicatively separable in what he calls discretionary (included in production function) and nondiscretionary (used to explain variations in efficiency) inputs. Analysis of the effects of firm-specific factors on economic efficiency has generated considerable debate in frontier studies. In this study, the two-step procedure has been adopted to analyze the effects of socioeconomic factors in the economic efficiency of the wheat producers. The economic efficiency estimates obtained are regressed on some socioeconomic factors using the Tobit model. This use of a second stage regression model of determining the socioeconomic attributes in explaining inefficiency has been suggested in a number of studies (e.g., $[24,25])$.

The Tobit Model. Consider the theoretical Tobit model, which takes the following form:

$$
Y_{k}^{*}=X_{k} \beta+U_{k}
$$

where $Y_{k}$ is the latent (hidden) independent variable for the $k$ th farm; $X_{k}$ is the vector of independent variables which have been postulated to affect efficiency.

The vector $\beta$ comprises the unknown parameters associated with the independent variables for the $k$ th farm and $U_{k}$ is an independently distributed error term assumed to be normally distributed with zero mean and constant variance. Dummy variables were added to represent the various socioeconomic factors such as age, gender, and level of education of the head of household among others. Because the dependent variable in (13) is a measure of efficiency, the variables with a negative (positive) coefficient will have a positive (negative) effect on efficiency levels.

3.4. Data and Sampling Procedure. The study was carried out in Rongai and Ngata divisions in the new Nakuru district where a representative sample of 138 wheat farmers was randomly selected. The district covers an area of $1484.1 \mathrm{~km}^{2}$ where $796.23 \mathrm{~km}^{2}$ is arable land, $45 \mathrm{~km}^{2}$ is water mass, forests are $7 \mathrm{~km}^{2}$, and national parks cover $188 \mathrm{~km}^{2}$. The district is located in the high potential (over 1,800 meters above sea level) and low potential (less than 1,800 meters above sea level) agroecological zones. The high potential zone generally receives more rainfall over a longer period of time than the low potential zone. The average farm size for small scale is 2.5 acres while for large scale is 200 acres. The district has three districts agroecological zones: lower highland (LH3-LH4), mainly the wheat/maize/barley zone, the lower midland 
(LM3) zone, and the upper midland (UM2-5) which is the upper sisal zone. According to the Ministry of Agriculture, these two divisions produce $75 \%$ and $25 \%$ of the total wheat produced in the district, respectively. A list of farmers in the district was provided by the Ministry of Agriculture at the divisional offices that was used to select the sampled farmers.

The sampling procedure used was stratified proportional sampling method since the population of the wheat farmers was not homogeneous. The sampling frame comprised all wheat farmers (in the 2008 season) in Ngata and Rongai divisions. Two separate lists from the sampling frame were developed. One list consisted of all the farmers who grew wheat on more than twenty $(>20)$ acres to form the first strata while the second list comprised farmers growing wheat on twenty acres and less (20 and less) of land. The sample size was determined using a formula developed by Krejcie and Morgan [26] which is shown as follows:

$$
S=\frac{\chi^{2} N P(1-P)}{d^{2}(N-1)}+\chi^{2} P(1-P),
$$

where $S=$ required sample size; $\chi^{2}=$ table value of chi-square for 1 degree of freedom at the desired confidence level which is 3.841 for $95 \%$ confidence level; $P=$ population proportion assumed to be 0.5 since this would provide the maximum sample size; $D=$ degree of accuracy expressed as a proportion (0.05); and $N=$ population of wheat farmers in the division.

Using the above formula, the sample size computed for a population of 150 small scale farmers was 108 farmers while the sample size for the 30 large scale farmers was 28 farmers. Ngata division had more large scale and small scale farmers than Rongai division. Therefore, to determine the sample size for each division for the small scale farmers the sampling was proportional to size at $60 \%$ for Ngata division and $40 \%$ for Rongai Division. For the large scale farmers the proportion was $57 \%$ in Ngata division and $43 \%$ in Rongai division. The farmers were then randomly selected from each stratum using the proportionate random sampling to form the study sample. A total number of 138 farmers were sampled.

The household data was collected using a structured questionnaire by trained enumerators. The survey sought information on wheat acreages, quantity of inputs and their prices, quantity harvested, credit, extension, and demographic characteristics of household members as well as the quality of life indicators.

The data was compiled and cleaned using SPSS data entry builder and SPSS data editor. The analysis was done using Frontier 4.0 and STATA statistical packages.

\section{Key Results and Discussion}

This section highlights the key results on the production systems, productivity, and efficiency levels.

4.1. Production Systems and Farmers' Profile. Majority of the farmers (both small scale and large scale) were growing wheat on rented land. The high cost of renting land had implications on the area that farmers were able to put under production.
Wheat production was highly mechanized with most of the farm activities being carried out by use of tractors. The large scale farmers reported high use of inputs such as certified seeds and fertilizers while most small scale farmers used recycled seeds during planting. The main reason for the use of recycled seeds was that they were cheaper than the purchased hybrid seeds. As a result, the productivity among the small scale farmers was lower than the large scale farmers. Wheat productivity in the district was below the normal yields mainly due to inadequate rainfall during the 2007 cropping season. The use of inputs such as certified seeds was quite low and farmers relied on recycled seeds. Fertilizer use was also low especially among the small scale farmers. The main cost components were cost of chemicals, land preparation costs, and fertilizer and seed costs.

Majority of the farmers had achieved the primary level of education. The literacy level determines the rate and extent of technology adoption and, with such level of education, the uptake of technology can be enhanced. Most farmers were self-employed in agriculture implying that they were available on their farms most of the times. The results indicate that most farmers were not accessing extension services mainly due to unavailability of extension workers and farmers had to travel long distances to access extension advice. Similarly, few farmers accessed credit facilities mainly due to lack of collateral and very strict conditions of accessing credit. On average, the gross margins were Kenya shilling 9,787 and Kenya shilling 7,260 per acre for large scale and small scale farmers, respectively. All other costs held constant; the gross margins looks attractive for both categories of farmers. This indicates that wheat production can be a profitable enterprise among the small scale farmers. With the supply of labor in the rural areas, the small scale farmers would manage to produce wheat in a cost-effective manner. This argument is supported by maize sector Kenya where majority of the farmers are small scale farmers practicing labor-intensive farming techniques and they supply the bulk of maize produced in the country.

4.2. Technical, Allocative, and Economic Efficiencies. The maximum-likelihood (ML) estimates of the parameters of the stochastic production frontier were obtained using the program FRONTIER 4.1 [17]. These results are presented in Table 1 which also presents the OLS results of the average production function for comparison. The signs of the slope coefficients of both OLS and ML estimates are positive except for family labor that has a negative coefficient implying that increasing the family labor affects wheat production negatively. ML estimated coefficients such as seeds, fertilizers, and chemicals are significant while for OLS only chemicals coefficient is statistically significant. The estimate of the variance parameter gamma $(\gamma)$ is also significantly different from zero, which implies that the inefficiency effects are significant in determining the levels of wheat output of the sampled farmers. The estimated production function is given as

$$
\begin{aligned}
\ln Y_{i}= & 4.5+0.48 \ln \text { seed }_{i}+0.11 \ln \text { fert }_{i} \\
& +0.11 \ln \text { chem }_{i}+0.09 \ln \text { foliar }_{i} \\
& +0.04 \ln \text { hiredlab }_{i}-0.027 \text { ln } \text { famlabor }_{i}
\end{aligned}
$$


TABLE 1: Ordinary least squares (OLS) estimates of the average production function and ML estimates of the stochastic production frontier for the sampled wheat producers.

\begin{tabular}{|c|c|c|c|c|c|c|}
\hline \multirow{2}{*}{ Variable } & \multicolumn{2}{|c|}{ OLS estimates } & \multirow{2}{*}{$t$-ratio } & \multicolumn{2}{|c|}{ ML estimates } & \multirow{2}{*}{$t$-ratio } \\
\hline & Coefficient & Standard error & & Coefficient & Standard error & \\
\hline Intercept & 4.59 & 1.003 & 4.57 & 4.46 & 0.882 & 5.06 \\
\hline lnseed & 0.28 & 0.228 & 1.24 & 0.48 & 0.205 & $2.35^{*}$ \\
\hline lnfertilizer & 0.08 & 0.054 & 1.49 & 0.11 & 0.043 & $2.63^{*}$ \\
\hline lnfoliar & 0.1 & 0.114 & 0.89 & 0.09 & 0.083 & 1.13 \\
\hline lnchemical & 0.19 & 0.066 & $3.02^{*}$ & 0.11 & 0.042 & $2.64^{*}$ \\
\hline lnhiredlabor & 0.04 & 0.029 & 1.52 & 0.04 & 0.025 & 1.76 \\
\hline lnfamilylabor & -0.04 & 0.034 & -1.34 & -0.027 & 0.031 & -0.85 \\
\hline sigma squared & 0.54 & & & 1.26 & 0.216 & 5.82 \\
\hline $\operatorname{gamma}(\gamma)$ & - & & & 0.93 & 0.036 & $2.59^{*}$ \\
\hline Log likelihood & -140.54 & & & -131.2 & & \\
\hline
\end{tabular}

${ }^{*}$ Significant at the $5 \%$ level.

where $Y_{i}=$ wheat output per acre in kilograms; seed $_{i}=$ quantity of seeds per acre in kilograms; fert $_{i}=$ the quantity of fertilizer per acre in kilograms; foliar ${ }_{i}=$ the quantity of foliar used per acre in kilograms; chem $_{i}=$ the quantity of chemicals used per acre in liters; hiredlab $b_{i}=$ the cost of hired labor per acre; famlabor ${ }_{i}=$ the imputed cost of family labor per acre.

The dual cost frontier derived from the stochastic production frontier, shown in Table 1, is as follows:

$$
\begin{aligned}
\ln C_{i}= & -1.507+0.267\left(\text { pseed }_{i}\right)+0.010\left(\text { pfert }_{i}\right) \\
& +0.012\left(\text { pfoliar }_{i}\right)+0.223\left(\text { pchem }_{i}\right) \\
& +0.147\left(\ln \text { pwage }_{i}\right)+1.042\left(\ln Y_{i}^{*}\right),
\end{aligned}
$$

where $C_{i}=$ the cost of production per acre of $i$ th farm; pseed $_{i}$ $=$ the price of seed per kg; pfert $_{i}=$ the price of fertilizer per $\mathrm{kg} ; \operatorname{pfoliar}_{i}=$ the price of foliar per kg; $\operatorname{pchem}_{i}=$ the price of chemical per liter; pwage $_{i}=$ the wage rate per day; $Y_{i}^{*}=$ the wheat output in $\mathrm{kg}$ per acre adjusted for statistical noise (Table 2).

4.3. Distribution of Technical Efficiency (TE), Allocative Efficiency (AE), and Economic Efficiency (EE) Measures. Results as indicated in Table 3 show that the mean technical, allocative, and economic efficiency indices of small scale wheat farmers are $85 \%, 96 \%$, and $84 \%$, respectively, while for the large scale farmers the mean technical, allocative, and economic efficiency indices are 91\%, 94\%, and $88 \%$. Thus the results from both small and large scale farmers reveal some considerable levels of inefficiencies in wheat production in Nakuru District. However, the large scale farms have relatively higher technical and economic efficiencies compared to small scale farmers.

The mean technical efficiency scores were quite high for both small and large scale farmers but were higher among large farms than for the small farms. However, the results show that there is still some considerable level of inefficiencies in the use of inputs for the corresponding output levels. The allocative efficiency was higher among small scale farmers than for large scale farmers implying that small scale farmers
TABLE 2: The OLS estimates of the stochastic cost function.

\begin{tabular}{lcccc}
\hline Cost per acre & Coefficient & Standard error & $t$ & $P>t$ \\
\hline lnpseed & 0.267 & 0.15 & 1.76 & 0.08 \\
lnpfertilizer & 0.010 & 0.03 & 0.34 & 0.731 \\
lnpfoliar & 0.012 & 0.01 & 0.89 & 0.378 \\
lnpchemical & 0.223 & 0.05 & 4.35 & 0.000 \\
lnplabor & 0.147 & 0.27 & 0.54 & 0.589 \\
lnobserved $Y^{*}$ & 1.042 & 0.13 & 7.78 & 0.000 \\
Constant & -1.507 & 1.82 & -0.83 & 0.410 \\
\hline
\end{tabular}

TABLE 3: Mean TE, AE, and EE scores by farm size.

\begin{tabular}{lccc}
\hline Farm size & TE & AE & EE \\
\hline Small scale & 0.85 & 0.96 & 0.84 \\
Large scale & 0.91 & 0.94 & 0.88 \\
Overall & 0.88 & 0.95 & 0.86 \\
\hline
\end{tabular}

were quite price-sensitive to the input prices than the large scale farmers. The overall economic efficiency was quite high for both farm categories though it was higher among large scale than small scale farmers. The mean technical, allocative, and economic efficiency estimates between large and small scale farmers was statistically significant.

The relatively high levels of technical efficiencies among the small scale farmers defies the notion that wheat production in the country can only be efficiently produced by the large scale farmers. This study shows that it is possible for small scale farmers to produce wheat efficiently. In many parts of Africa including Kenya small farms remain at the center of agriculture and rural development. However, one of the main causes for the low agricultural productivity is the lack of appropriate machineries that cater to and suit the requirements of small scale farms. For this reason, many small farms are deemed as unproductive and inefficient. To raise the productivity of wheat among small scale farmers in the country basic farm mechanization requirements to cater to small farm needs must be met, such as suitability to small farms; simple design and technology; versatility 
for use in different farm operations; affordability in terms of cost to farmers; and, most importantly, the provision of support services from the government and the private sectors/manufacturers.

4.4. Farm Size and Efficiency. Statistical tests were carried out on the relationship between the size of the farm and technical efficiency. The test results shows that the mean differences in technical scores are significantly different from zero at $1 \%$ and $5 \%$ levels of significance. The null hypothesis that the mean difference equals zero is rejected, thus accepting the alternative that the mean difference between small scale and large scale is less than zero. These results indicate that large scale farms have a higher technical efficiency than small scale farms. Results on the statistical tests on the association between farm size and allocative efficiency show that the mean difference in allocative efficiency scores is statistically different from zero at $1 \%$ and $5 \%$ level of significance. The null hypothesis that there is no mean difference between small scale and large scale is rejected. This implies that there is statistical difference in allocative efficiencies between small scale and large scale wheat farms. A similar test was done on the association between farm size and economic efficiency. The results show that the mean difference in economic efficiency scores between small scale and large scale farmers is statistically different from zero at $1 \%$ and $5 \%$ levels of significance. The null hypothesis is rejected and this implies that the large scale farmers have higher economic efficiency than small scale farmers.

4.5. Findings on Factors Influencing Efficiency. For this purpose, the parameters technical efficiency (TE), allocative efficiency (AE), and economic efficiency (EE) indices were estimated censured Tobit procedure for the following socioeconomic characteristics:

(1) farm size, equal to zero for small scale and equal to one for large scale;

(2) age, given by age of the household head;

(3) gender, equal to zero for female head and one for male head;

(4) marital status, equal zero for single, one for married, and two for widowed;

(5) level of education of head, equal to zero for no education, one for primary education, and two for postprimary education;

(6) main occupation of household head, equal to zero for salaried and one for self-employed;

(7) belonging to a farmer group, equal to zero for No and one for Yes;

(8) distance to the nearest certified seed seller $(\mathrm{km})$;

(9) distance to nearest extension services $(\mathrm{km})$;

(10) land tenure, equals zero for owned land and one for rented land;

(11) source of seed, equal to zero for recycled seed and one for purchased seed.
The Tobit results presented in Table 4 show that there is the lack of consistent pattern of association between efficiency and some socioeconomic characteristics such as farm size, age of the head, and years of experience in growing wheat. The clearest pattern that emerges is that most of these socialeconomic characteristics were positively related to efficiency. The positive sign of farm size implies that technical efficiency increases with the size of the farm. The size of the farm is also significant with allocative efficiency. The negative sign for the age of the head implies that efficiency of production declined with the age of the head. The significant influence of education on farm efficiency is critical indicating that households headed by more educated heads were more educated compared with households headed by less educated heads. The interpretation is that farmers who had a higher level of training were more technically and economically efficient than those with low level of training.

The positive relationship between the education level of household head and economic efficiency can be supported by similar results reported in studies which have focused on the association between formal education and technical efficiency [18, 27, 28]. In general, more educated farmers are able to perceive and interpret and respond to new information and adopt improved technologies such as fertilizers, pesticides, and planting materials much faster than their counterparts. This result is consistent with the findings by Abdulai and Eberlin [29] which established that an increase in human capital will augment the productivity of farmers since they will be better able to allocate family-supplied and purchased inputs and select and utilize the appropriate quantities of purchased inputs while applying available and acceptable techniques to achieve the portfolio of household pursuits such as income. The result that shorter distances to extension providers influenced farm efficiency is also consistent with findings by Seyoum et al. [30] who found a $14 \%$ difference in technical efficiency between farmers who had access to extension services and those who did not in a study on farmers within and outside the Sasakawa Global 2000 project. Extension workers play a central role in informing, motivating, and educating farmers about available technology.

\section{Conclusions}

The relationship between farm size and efficiency is one of the more persistent puzzles in development economics, even more so as many potential determinants have been put forward and tested without being able to provide a fully satisfying explanation. The findings from this study suggest that gains from improving technical efficiency exist in all farm categories but they appear to be much higher on large than on small farms. While small farms tend to use land more intensively in an attempt to alleviate land constraints, the study suggests that the relatively higher level of technical efficiency observed on small farms is largely attributable to the adoption of traditional land saving techniques rather than the use of modern land saving technologies. Small scale farms are found to be more allocatively efficient than 
TABLE 4: Tobit model estimates for different efficiency measures.

\begin{tabular}{|c|c|c|c|c|c|c|}
\hline \multirow{2}{*}{ Variable } & \multicolumn{2}{|c|}{ Technical efficiency } & \multicolumn{2}{|c|}{ Allocative efficiency } & \multicolumn{2}{|c|}{ Economic efficiency } \\
\hline & Coefficient & $t$-ratio & Coefficient & $t$-ratio & Coefficient & $t$-ratio \\
\hline Farm size & 0.00 & $(0.06)$ & $0.02^{*}$ & $(1.90)$ & 0.01 & $(1.37)$ \\
\hline Age of head & -0.00 & $(0.10)$ & 0.00 & $(0.84)$ & 0.00 & $(0.16)$ \\
\hline Gender & 0.01 & $(0.13)$ & -0.00 & $(0.20)$ & -0.00 & $(0.20)$ \\
\hline Marital status & -0.05 & $(1.25)$ & 0.03 & $(1.59)$ & 0.00 & $(0.03)$ \\
\hline Education & $0.04^{* *}$ & $(2.36)$ & -0.01 & $(1.51)$ & $0.01^{* * *}$ & $(2.62)$ \\
\hline Main occupation & 0.00 & $(0.10)$ & $-0.00^{*}$ & $(1.21)$ & 0.01 & $(1.39)$ \\
\hline Belonging to group & -0.01 & $(0.62)$ & 0.01 & $(1.37)$ & 0.00 & $(0.38)$ \\
\hline Distance to extension service & $-0.00^{*}$ & $(1.77)$ & -0.00 & $(1.46)$ & $-0.00^{* *}$ & $(2.26)$ \\
\hline Distance to certified seed seller & -0.00 & $(0.95)$ & -0.00 & $(0.06)$ & 0.00 & $(0.95)$ \\
\hline Tenure & -0.00 & $(0.20)$ & -0.00 & $(0.31)$ & 0.00 & $(0.05)$ \\
\hline Seed source & -0.01 & $(0.81)$ & -0.00 & $(0.25)$ & -0.00 & $(0.16)$ \\
\hline Constant & $0.90^{* * *}$ & $(11.45)$ & $0.95^{* * *}$ & $(26.38)$ & $0.87^{* * *}$ & $(36.90)$ \\
\hline Observations & 129 & & 129 & & 129 & \\
\hline
\end{tabular}

Absolute value of $t$ statistics in parentheses; ${ }^{*}$ significant at $10 \% ;{ }^{* *}$ significant at $5 \% ;{ }^{* * *}$ significant at $1 \%$.

the larger farms. Nevertheless, gains from improving allocative efficiency exist in more than $90 \%$ of the sample households. Accordingly, measures aimed at reducing labor congestion on the farms, relaxing liquidity constraints, and improving the functioning of land rental markets can significantly improve productive efficiency. While self-sufficiency in wheat remains a stated goal of the government, it has remained elusive over the years. With current yields, self-sufficiency will be accomplished only if area under wheat is increased substantially or through intensification leading to higher yields.

Efforts should also be made to improve extension services, access to high yielding seed varieties, and proper cop husbandry methods. Opening up more areas in the potential wheat areas in the country, mostly in the marginal areas through irrigation, could assist in increasing output substantially faster than simply targeting policy interventions towards increased input use. The existing small scale wheat farmers should be supported in lowering their costs of production to ensure that they remain in production since their production will remain critical to the government's strategies on food security, poverty reduction, and increased rural employment.

\section{Conflict of Interests}

The authors declare that there is no conflict of interests regarding the publication of this paper.

\section{Acknowledgments}

The authors are grateful to CMAAE (Collaborative Masters in Applied Agricultural Economics) program for providing the financial assistance and to the paper reviewers for their objective comments on the earlier drafts.

\section{References}

[1] J. J. Assuncão and M. Ghatak, "Can unobserved heterogeneity in farmer ability explain the inverse relationship between farm size and productivity," Economics Letters, vol. 80, no. 2, pp. 189194, 2003.

[2] S. Dercon and P. Krishnan, "Income portfolios in rural Ethiopia and Tanzania: choices and constraints," Journal of Development Studies, vol. 32, no. 6, pp. 850-875, 1996.

[3] C. B. Barrett, "On price risk and the inverse farm sizeproductivity relationship," Journal of Development Economics, vol. 51, no. 2, pp. 193-215, 1996.

[4] J. J. Assunção and L. H. B. Braido, "Testing household-specific explanations for the inverse productivity relationship," The American Journal of Agricultural Economics, vol. 89, no. 4, pp. 980-990, 2007.

[5] M. Lipton, "From policy aims and small-farm characteristics to farm science needs," World Development, vol. 38, no. 10, pp. 1399-1412, 2010.

[6] C. B. Barrett, M. F. Bellemare, and J. Y. Hou, "Reconsidering conventional explanations of the inverse productivity-size relationship," World Development, vol. 38, no. 1, pp. 88-97, 2010.

[7] F. Byiringiro and T. Reardon, "Farm productivity in Rwanda: effects of farm size, erosion, and soil conservation investments," Agricultural Economics, vol. 15, no. 2, pp. 127-136, 1996.

[8] R. L. Lamb, "Inverse productivity: land quality, labor markets, and measurement error," Journal of Development Economics, vol. 71, no. 1, pp. 71-95, 2003.

[9] P. Collier and S. Dercon, "African agriculture in 50 years: smallholders in a rapidly changing world," in Paper Presented at the 2009 Food and Agriculture Organization Expert Meeting on How to Feed the World in 2050, 2009.

[10] J. Nyoro, M. Muyanga, and I. Komo, "Wheat and wheat products trade in Kenya," Tech. Rep., Cereal Growers Association, Cereal Millers Association and Tegemeo Institute, 2005.

[11] G. A. Obare, D. O. Nyagaka, W. Nguyo, and S. M. Mwakubo, "Are Kenyan smallholders allocatively efficient? Evidence from 
Irish potato producers in Nyandarua North district," Journal of Development and Agricultural Economics, vol. 2, no. 3, pp. 078085, 2010.

[12] R. Mulwa, A. Emrouznejad, and L. Muhammad, "Economic efficiency of smallholder maize producers in Western Kenya: a DEA meta-frontier analysis," International Journal of Operational Research, vol. 4, no. 3, pp. 250-267, 2009.

[13] B. Abate, F. Machel, and A. Gezahegn, "Effect of Farm Size on Technical Efficiency of Teff Production: A case Study of the Moretina Jiru District, Central Ethiopia," 2006.

[14] K. Ogundari and S. Ojo, "Economic Efficiency of small scale food crop production in Nigeria: a stochastic frontier approach," Journal of Social Sciences, vol. 14, no. 2, pp. 123-130, 2007.

[15] R. J. Kopp and W. E. Diewert, “The decomposition of frontier cost function deviations into measures of technical and allocative efficiency," Journal of Econometrics, vol. 19, no. 2-3, pp. 319331, 1982.

[16] M. J. Farrell, "The measurement of productive efficiency," Journal of the Royal Statistical Society Series A, vol. 120, pp. 253290, 1957.

[17] T. J. Coelli, A Guide to FRONTIER Version 4.1: A Computer Program for Stochastic Frontier Production and Cost Function Estimation, Department of econometrics, University of New England, Armidale, Australia, 1994.

[18] B. E. Bravo-Ureta and R. E. Evenson, "Efficiency in agricultural production: the case of peasant farmers in eastern Paraguay," Agricultural Economics, vol. 10, no. 1, pp. 27-37, 1994.

[19] B. E. Bravo-Ureta and L. Rieger, "Dairy farm efficiency measurement using stochastic frontiers and neoclassical duality," American Journal of Agricultural Economic, vol. 73, no. 2, pp. 421-428, 1997.

[20] P. Drysdale, K. P. Kalirajan, and S. Zahao, "The impact of economic reform on production growth in Chinese agriculture," American Journal of Agricultural Economics, vol. 73, no. 2, pp. 266-275, 1995.

[21] G. E. Battese and G. S. Corra, "Estimation of a production frontier model: with application to the Pastoral Zone of Eastern Australia," Australian Journal of Agricultural Economics, vol. 21, no. 3, pp. 169-179, 1977.

[22] K. P. Kalirajan, "The importance of efficient use in the adoption of technology: a micro panel data analysis," Journal of Productivity Analysis, vol. 2, no. 2, pp. 113-126, 1991.

[23] S. C. Ray, "Data envelopment analysis, nondiscretionary inputs and efficiency: an alternative interpretation," Socio-Economic Planning Sciences, vol. 22, no. 4, pp. 167-176, 1988.

[24] K. R. Sharma, P. Leung, and H. M. Zaleski, "Technical, allocative and economic efficiencies in swine production in Hawaii: a comparison of parametric and nonparametric approaches," Journal of Agricultural Economics, vol. 20, no. 1, pp. 23-35, 1999.

[25] B. R. Dhungana, P. L. Nuthall, and G. V. Nartea, "Measuring the economic inefficiency of Nepalese rice farms using data envelopment analysis," The Australian Journal of Agricultural and Resource Economics, vol. 48, no. 2, pp. 347-369, 2004.

[26] R. V. Krejcie and D. W Morgan, "Determining sample size for research activities," Education and Psychological Measurement, vol. 30, pp. 607-610, 1970.

[27] R. W. Uaiene and C. Arndt, "Farm household technical efficiency in Mozambique," in Contributed Paper for Presentation at the IAAE Conference, Beijing, China, August 2009.

[28] M. Bozoglu and V. Ceyhan, "Measuring the technical efficiency and exploring the inefficiency determinants of vegetable farms in Samsun province, Turkey," Agricultural Systems, vol. 94, no. 3, pp. 649-656, 2007.

[29] A. Abdulai and R. Eberlin, "Technical efficiency during economic reform in Nicaragua: evidence from farm household survey data," Economic Systems, vol. 25, no. 2, pp. 113-125, 2001.

[30] M. J. Seyoum, G. E. Battese, and E. M. Fleming, “Technical efficiency and productivity of maize producers in eastern Ethiopia: a study of farmers within and outside the SasakawaGlobal 2000 project," Agricultural Economics, vol. 19, no. 3, pp. 341-348, 1998. 


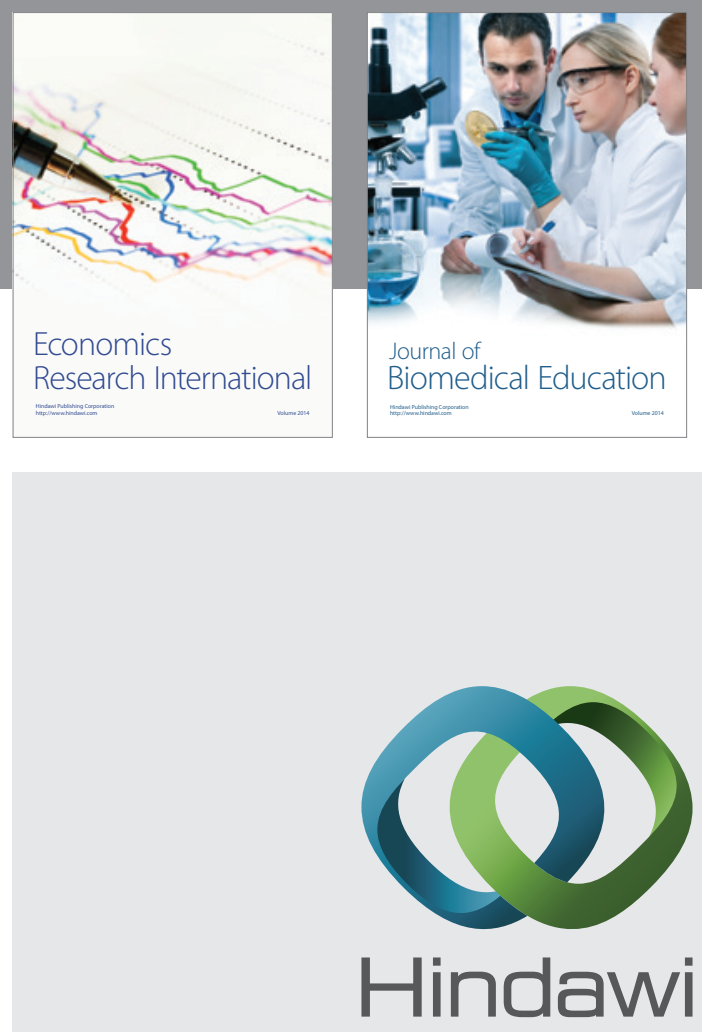

Submit your manuscripts at

http://www.hindawi.com
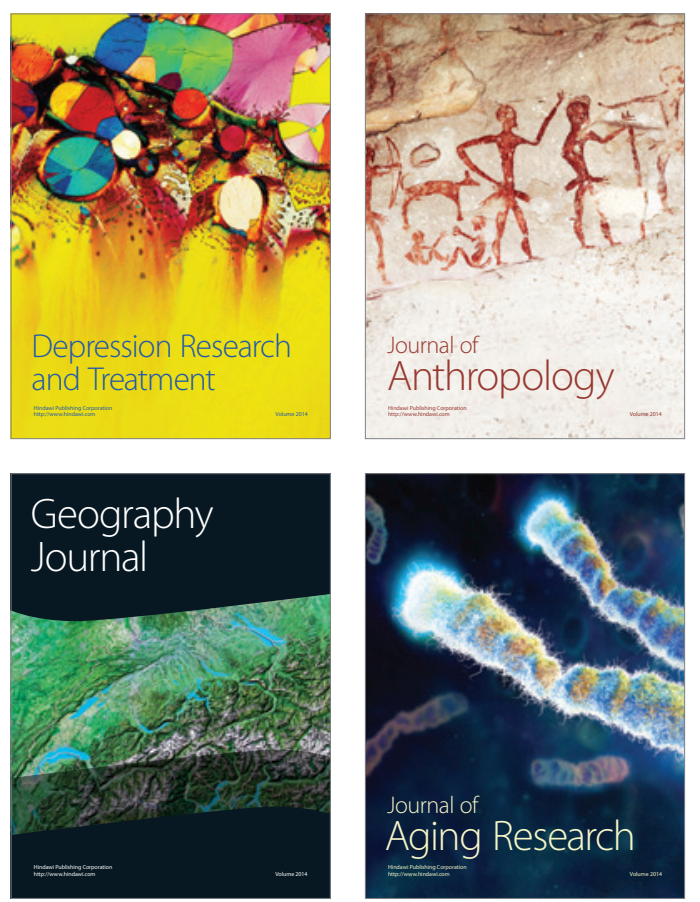


(D)
